\title{
La revitalización económica de los centros históricos como logro de la confluencia de las políticas municipales y los intereses privados. La ciudad de Málaga: una vía hacia la gestión mancomunada del espacio
}

\section{Carmen Criado Cañas y Ana Rubio Florido *}

\section{Introducción}

La evolución del Centro Histórico de Málaga es fruto de la dinámica interna de la ciudad en la que existe una tensión permanente, la tensión del cambio, entre una realidad socioeconómica cambiante y una estructura física más rígida (TROITINO, 1997). A partir de la década de los años sesenta, con los planes de desarrollo y el inicio del boom turístico en Málaga, se produce un auge económico en la ciudad, que tiene como consecuencia más directa (hasta avanzada la década de los noventa) un modelo de ciudad expansionista que deja en el olvido a la ciudad histórica y más concretamente al núcleo histórico. Esta situación producirá un desequilibrio en la ciudad en la que se intentará crear ex novo una nueva centralidad urbana.

En este período se produce en el centro histórico:

- Un fuerte vaciamiento demográfico. El progresivo abandono de los residentes llega a su nivel más crítico en el período 1975-1980, quedando, a partir de esta fecha, como residentes la población «atrapada», es decir, aquella que no ha podido marcharse por cuestiones como una edad elevada o debido a un bajo nivel adquisitivo.
- La degradación física de los inmuebles y del entorno. El escaso número de residentes y el debilitamiento de su actividad económica propician una continuada degradación física, producto de la ausencia de inversiones tanto públicas como privadas.

- El debilitamiento de la actividad económica. Con las primeras señales de deterioro físico, el abandono de instituciones públicas del centro hacia nuevas zonas de la ciudad, el elevado número en la implantación de nuevos espacios comerciales (grandes almacenes, grandes superficies y centros comerciales cerrados, según el Plan Integral de Fomento del Comercio Interior de Andalucía 1998-2001, Málaga ocupa el segundo puesto a nivel nacional en superficie de venta de hipermercados por cada 10.000 habitantes) y la carencia de equipamientos básicos, como aparcamientos, produjo un lento pero prolongado declive de la actividad económica, siendo el más perjudicado el sector comercial.

- La aparición de marginalidad y bolsas de pobreza. Con el deterioro físico y la pérdida del uso residencial se produce en las zonas de menor presencia de la actividad económica la aparición de una marginalidad (asociada a las drogas y la prostitución) que agudizó la crisis del centro histórico. 
Dentro de esta dinámica, justo en el período más crítico (1975-1980) surge el movimiento asociativo empresarial en el Centro Histórico de Málaga. Fue la iniciativa privada la primera en reaccionar ante una situación de abandono que de no corregirse acabaría con la existencia del centro histórico como un espacio relevante en valores patrimoniales, funcionales y simbólicos.

\section{Evolución de la Asociación}

En el año 1977 se constituye en Málaga la asociación Gran Centro Comercial de Málaga, con carácter territorial y circunscrita al perímetro del Núcleo Histórico de ésta. El ámbito de actuación de la asociación coincide con la delimitación de la ciudad intramuros nazarí, concretamente la medina musulmana, siglo xv. Hacemos referencia a la primera asociación territorial que se constituye en Andalucía, precedida únicamente a nivel nacional por la Asociación Casco Viejo de Bilbao y Barna Centre en Barcelona.

Los objetivos principales recogidos en sus estatutos se resumen en las siguientes líneas:

- Informar y asesorar para la mejora de la gestión interna de las actividades mercantiles y profesionales.

- Establecer una línea de interlocución, asociación-administraciones públicas. Participando en el estudio y solución de los problemas que afectan al sector y promoviendo propuestas y medidas que se estimen oportunas y necesarias para el desarrollo de la zona.

- Promover la mejora y realización de los equipamientos e infraestructuras necesarias, prestando especial atención a la dotación de una amplia oferta de aparcamientos y ampliación de los transportes públicos.

Tras diecinueve años de experiencia asociativa, y a causa de los cambios económicos, sociales y culturales que se producen a lo largo de estas dos últimas décadas, se genera en la asociación una necesidad de renovación que se materializa en 1.996, produciéndose una transformación profunda que lleva a un cambio en su denominación, a una reforma de sus estatutos y una reformulación y ampliación de sus objetivos.

La nueva denominación «Centro Histórico de Málaga» responde a la recuperación del valor añadido de lo histórico. Reaparece culturalmente en los ciudadanos la concepción de la centralidad histórica. Este cambio es promovido, sobre todo, por la asociación de empresarios del centro histórico (inversiones privadas, campañas de animación, publicidad y difusión).
Se produce una puesta en valor del patrimonio histórico-cultural, entendiéndose éste como un valor añadido que se incorpora tanto al conjunto del espacio (singularizándolo del resto de la ciudad) como a las actividades económicas que se desarrollan en él.

Con el cambio estatutario de la asociación se ampliaron los fines y objetivos de ésta. Se mantiene su carácter comercial y empresarial a la vez que se incorpora los aspectos: social, turístico y cultural.

\section{A los objetivos primigenios se incorporan:}

- Cooperar, asesorar y participar activamente en el desarrollo y puesta en práctica de cualquier actividad, normativa, plan o reglamento que afecte al centro bistórico o a los intereses de sus asociados en su conjunto, asi como promociones comerciales y campañas que fueran de interés.

- Poner en valor el Centro Histórico de Málaga para conseguir llegar a alcanzar niveles de un Centro Histórico Europeo del siglo XXI sin olvidar las tradiciones, bistoria y pasado de nuestra ciudad.

- Cuantos fines puedan conseguirse a través de la Asociación en orden a la defensa de los intereses de todos los asociados y de la ciudad de Málaga.

Los servicios prestados por la asociación a lo largo de su historia fueron incrementándose, a medida que se consolidaban las estructuras internas y en función de las necesidades demandadas por el colectivo. El asesoramiento personalizado a los comerciantes; convenios con entidades financieras, para ofertar al asociado productos a interés preferencial; realizaciones de estudios de investigación comercial de la situación de la oferta de nuestro espacio (Informe Capezco, Iresco, 1980; Estudio de investigación sobre la actividad comercial y de servicios en el centro histórico de Málaga, 1991; convenio de colaboración con la Universidad de Málaga y la puesta en práctica de una Oficina Técnica de la Asociación, 1997); tarjeta de compras como elemento de fidelización de clientes, y la siempre manifiesta defensa de los intereses del espacio ante la Administración Pública, que la hacía estar presente en los foros de discusión y debate de la ciudad, en una continua presencia y actitud participativa: en los Planes de Ordenación Urbana de la ciudad, en el Plan de Protección y Reforma Interior del Centro Histórico, en el debate y mesas de trabajo del Plan Estratégico de Málaga, en la Iniciativa Comunitaria Urban; por lo que de manera continuada la Asociación ha estado presente en las entidades y organismos tanto públicos como privados de la ciudad, con objeto de «guiar» y promover las actuaciones urbanísticas y de mejora del entorno, en general, del centro histórico necesarias para el comercio.

A lo largo de su historia esta asociación ha recibido diversas distinciones por las actividades y servicios que ha desarrollado, entre otras, la designación de Primer Centro Comercial Piloto 
de Andalucía, otorgado por la Consejería de Comercio de la Junta de Andalucía, en el año 1983, y el Primer Premio Nacional de Comercio Interior 1997, otorgado por la Dirección General de Comercio Interior, Secretaría de Estado de Comercio, Turismo y PYME, Ministerio de Economía y Hacienda, en el año 1998.

\section{Iniciativas para la revitalización del centro histórico}

La revitalización del centro histórico debe basarse en la creación y aplicación efectiva de las políticas municipales, la colaboración mutua en las iniciativas reactivadoras y en la confluencia de las inversiones públicas y privadas.

\subsection{Iniciativas de la Asociación Centro Histórico con la colaboración del Ayuntamiento de Málaga}

A principios de la década de los ochenta, con el establecimiento de las relaciones entre Asociación y Ayuntamiento, se consigue llevar a cabo dos acciones fundamentales de importante repercusión en la reactivación del centro histórico.

- Inversión del tráfico rodado expulsivo, de carácter manifiestamente disuasorio. Se mantienen conversaciones con el Ayuntamiento para la variación del tráfico rodado, para modificar los accesos de entrada al centro, que hasta ese momento se producía en una circulación periférica cuyo único objetivo era la expulsión de los vehículos privados. Se consiguió el cambio de esta política municipal disuasoria, mediante la nueva reorganización del tráfico rodado en el interior del casco que permitió crear el acceso principal de entrada por la calle más emblemática de la ciudad (calle Marqués de Larios). Esto supuso para el visitante una nueva percepción, muy positiva, al crear una «puerta de entrada» al centro.

- La renovación del alumbrado público mediante la inversión privada. El deterioro físico del casco a principios de los ochenta, incluía un deficiente equipamiento en el mobiliario urbano. Existía en el centro un grave problema por el insuficiente alumbrado público cuya consecuencia principal era una elevada inseguridad ciudadana. Debido a la falta de inversión del Ayuntamiento en el centro histórico (en este período la mayor parte de las inversiones municipales van dirigidas a dotar de equipamientos e infraestructuras a la nueva ciudad que se crea en los años sesenta y setenta) es el agente privado el que toma la iniciativa en la renovación del alumbrado público. La Asociación promueve entre los comerciantes la inversión privada en el espacio público. Se realiza una importante inversión para la adquisición de lámparas que sustituyan las existentes. En la actualidad (después de veinte años) se mantiene este alumbrado en un número importante de calles.

\section{La creación de la feria en el centro bistórico}

En los meses de verano, especialmente en el mes de agosto, se producía un importante descenso tanto de residentes como de visitantes en el centro histórico. Los residentes de nivel adquisitivo medio-alto se trasladaban a sus segundas residencias situadas en los municipios costeros colindantes a la ciudad de Málaga (con la construcción de las autovías a principios de la década de los noventa, estas segundas residencias se consolidarán como el área metropolitana de Málaga). El descenso en el número de visitantes, no dejaba de ser una paradoja, teniendo en cuenta que Málaga es uno de los destinos turísticos por excelencia a nivel nacional e internacional, pero la ciudad, y más concretamente su centro histórico, no contaba con el atractivo turístico necesario. Con objeto de invertir esta tendencia, la Asociación crea un plan de animación, con motivo de la Feria de Agosto de la ciudad, consistente en la puesta en marcha de una serie de actividades folklórico-festivas.

Las actividades consistieron en:

Circuitos por el centro de paseo de enganches y caballos debidamente engalanados. (Se contrataron los carruajes más relevantes de las provincias de Córdoba, Sevilla, Cádiz y Málaga.)

Organización y desarrollo del Concurso-Exhibición de Enganches en la Plaza de Toros de la Ciudad.

Actuaciones en calles y plazas de grupos folklóricos ataviados con los trajes típicos de la provincia y de la región.

Decoración de calles con farolillos y toldos para mitigar el calor.

A esta animación en calle, se sumaba el espíritu festivo creado por los comercios, que decoraban sus interiores a la vez que ofrecían a todos los visitantes vinos y tapas con el objeto de crear el ambiente típico de feria.

Todas estas actividades fueron planificadas por la asociación y cofinanciadas por ésta, el Ayuntamiento, la Diputación Provincial y entidades comerciales que instalaban sus casetas en las calles.

Este plan de animación, que no contó en sus primeros años con el apoyo total del Ayuntamiento, en pocos años fue con- 
solidándose en un fenómeno social de gran magnitud creándose la feria de día (centro histórico), que año tras año atraía a más visitantes, como alternativa a la feria ubicada en el recinto ferial, en las afueras de la ciudad. Así, la feria de día (a la que popularmente se la denomina «Feria del Centro») se convierte por su originalidad, al desarrollarse en el entorno urbano, en uno de los mayores atractores turísticos de la ciudad, recibiendo anualmente miles de visitantes nacionales e internacionales. Al convertirse en un fenómeno de masas, el Ayuntamiento pasa a ejercer el principal control de la nueva situación creada, asumiendo la organización de actividades, la decoración de las calles, regulando los horarios, los usos, etc. La Asociación mantiene aún una colaboración activa, organizando la Romería Urbana, la Elección y organización del Acto de Presentación del Abanderado de la Feria.

Este modelo de Feria fue implantándose en otros municipios de la provincia y ciudades andaluzas, no como un plan de animación de su centro histórico, sino como un fenómeno de atracción turística para la ciudad.

\section{Decoración Navideña}

Desde su creación, la Asociación asumió la organización de la campaña de Navidad en el Centro con el adorno de sus calles y plazas. En 1996 introduce un cambio en el diseño de los motivos decorativos de Navidad; esta innovación originó un gran impacto en la ciudad. El objetivo principal del nuevo diseño era diferenciar, en estas fechas, el centro histórico del conjunto de la ciudad.

Esta decoración tenía una serie de ventajas con respecto a la tradicional, en los siguientes aspectos:

- Un adorno basado en motivos decorativos donde no prima la iluminación, con lo que se consigue una recreación del ambiente navideño durante el día. voltaje.

- Un bajo consumo eléctrico, al ser las lámparas de bajo

Si bien la iniciativa surge de la Asociación, el Ayuntamiento acoge favorablemente el proyecto, por lo que se establece una colaboración económica para la compra del material, y en los últimos años para el almacenaje e instalación.

Se creó, con esto, la nueva imagen navideña del centro. En la actualidad este tipo de decoración navideña se ha implantado en otros municipios de la Costa del Sol, por lo que la Asociación está planificando junto con el Ayuntamiento una nueva estrategia de diferenciación para el centro histórico de Málaga.

\subsection{Iniciativas del Ayuntamiento con la colaboración de la Asociación Centro Histórico de Málaga}

\section{La evolución de los planes generales de ordenación urbana de Málaga}

La degradación física, social, económica y cultural a la que se llegó en el centro histórico se produjo sobre todo por la falta de planeamiento en su período más crítico (1955-1975, boom turístico de la Costa del Sol), en el que la ciudad se vio sometida a un rápido e incontrolado crecimiento expansivo, deslocalizador de su centralidad, no sólo ya desde el punto de vista geográfico, sino en sus funciones y poblamiento.

La ausencia de planeamiento se mantiene con un desafortunado PGO, que fue aprobado en 1950 por la Comisión Central de Sanidad Local. Este Plan nunca llegará a ser aplicado. En un principio porque no «convenía», por ser un momento especialmente dulce en los procesos especulativos que se estaban produciendo en la ciudad y más tarde por la sentencia emitida por el Tribunal Superior de Justicia en 1954, que anuló su validez legal. En 1971 se aprueba un nuevo PGO, cuyo objetivo principal es, por un lado, guiar el anárquico crecimiento de la ciudad y, por otro, dar infraestructuras y equipamiento a la reciente ciudad creada en los años anteriores. En ninguno de los dos planes se hace nada por evitar la dinámica degradante a la que se abocaba al centro histórico, ya que en el plan de 1950 a pesar de todo lo expuesto, éste excluía de su ámbito de influencia al centro histórico, y en el segundo, porque no «interesaba» rehabilitar espacios urbanos, sino construir nuevos.

La llegada de la democracia a nuestro país y el triunfo del Partido Socialista Obrero Español en el municipio de Málaga hicieron posible que se llevara a la práctica el «urbanismo alternativo». El cambio ideológico supone una ruptura con el modelo existente de ciudad expansionista, siendo el objetivo de este «nuevo urbanismo» la conservación y el uso correcto de la ciudad creada. Es acertado pensar que dentro de este marco teórico una de las máximas preocupaciones fue la recuperación del centro histórico de Málaga. Intención que quedó recogida en el PGOU de 1983, en el artículo 235 de su normativa: Recuperación y conservación de la estructura urbana y su tipología edificatoria mediante procesos de rehabilitación; control de las actividades terciarias, mantenimiento de la población, etc.

Para conseguir estos objetivos elabora el PGOU una normativa específica (Capítulo $4 .^{\circ}$ ), crea el marco jurídico-administrativo que regulará desde las condiciones de ordenación, las condiciones de edificación, las condiciones de uso en los edificios, la catalogación de las calles y alturas edificables permitidas según el grado al que éstas pertenezcan.

Además de esto, el Plan realiza una normativa específica para los edificios protegidos (Capítulo $3 .^{\circ}$ ) creándose dos nive- 
les de protección: por un lado, la protección integral, en la que se determina la conservación total del inmueble y, por el otro, la protección arquitectónica, que flexibiliza los usos y obras a realizar en los edificios catalogados como tales. Es necesario aclarar que los edificios del Núcleo Histórico que se hayan incluido en el catálogo del nivel de protección integral quedan sujetos a esta normativa, obviándose para ellos las normas que afectan a su zona.

Dos años después de la aprobación del PGOU de 1983, la Dirección General de Bellas Artes por Resolución del 18 de julio de 1985, publicada en el BOJA del 2 de agosto del mismo año, acordó tener incoado el expediente de declaración de Conjunto Histórico. A partir de ese momento gracias al artículo 11 de la Ley de Patrimonio se le concede al centro histórico la aplicación provisional del mismo régimen de protección previsto para los BIC, ya declarados. Esto conlleva, según se recoge en el artículo 20 de la Ley de Patrimonio, la obligación, por parte del municipio donde se localice el BIC, de realizar un Plan Especial de Protección del área incoada. Debido a esto se aprobó un Plan Especial, pero no únicamente de protección, sino que también incorpora en el mismo documento otro, de Reforma Interior. Creándose un PEPRI (1990), lo acertado de esta unión ha sido y es cuestionado por una gran parte de la sociedad malagueña. Si bien es sabido que la mayoría de las veces para conservar espacios urbanos hay que sacrificar determinados inmuebles y paisajes en bien de la generalidad del conjunto, esto está muy lejos de la aplicación de un Plan Especial de Reforma Interior, donde el objetivo básico es el derribo de edificios del área afectada para más tarde llevar a cabo tareas de reconstrucciones que implican desde realineamientos, modificaciones de las alturas, de tipologías, etc.

La Asociación Centro Histórico participó activamente en las reuniones de consenso para la elaboración de los dos instrumentos de planificación, anteriormente desarrollados, aunque su interés y actividad fue mayor en el PEPRI al ser éste un documento específico del centro y en el que en un primer momento se ponen muchas expectativas.

La Asociación mantuvo en estas reuniones de trabajo una postura inflexible con respecto a la dinámica de terciarización de los usos. La excesiva presencia de bancos, aseguradoras y oficinas en general, estaba generando ya en determinadas calles un incipiente proceso de desertización, ya que estas actividades tiene un horario de apertura sólo de mañanas, es, por esto, que donde se localizaban, con una densidad elevada, por las tardes se producía un abandono de personas que perjudica a la actividad comercial que compartía la calle con ellas. Como consecuencia de esta postura por parte de la Asociación, en el Plan de 1983 se incluye una limitación de usos en planta baja para ciertas calles del centro. Limitación que se hace más restrictiva en el PEPRI. Con esto se consiguió evitar en el centro de Málaga los intensos procesos de terciarización que se pro- dujeron en otras ciudades de España que fueron los causantes directos de la incorporación de grupos marginales en estas calles fuera del horario de la actividad de oficinas.

Si bien, en el planeamiento anterior, a petición de la Asociación se había limitado el uso en las calles más comerciales, de las actividades financieras, aseguradoras y de oficinas en general por sus repercusiones negativas, no se había previsto algo similar para la actividad de bares y restaurantes. A finales de la década de los ochenta comienzan a instalarse de manera masiva los bares de copas en el centro. Esta actividad degradó áreas enteras del casco, por el abandono de los residentes por los ruidos nocturnos, por el impacto de basuras, y por la ausencia de la actividad diurna. Se desertizaron calles completas que a finales de los noventa están totalmente degradadas física y funcionalmente. Con el objeto de poner fin a esta situación, desde la Asociación Centro Histórico se presentó un pliego de alegaciones (1994) al vigente PGOU (aprobado en 10 de julio de 1997) en el que se requería que la nueva planificación, ya que incorporaba un capítulo nuevo (Normativa Título XIII, Capítulo IV), de usos del centro histórico que modificaba los usos del PEPRI, fuera restrictiva tanto en la densidad de estos bares como en su prohibición en determinadas calles, tal y como se había hecho en la planificación anterior con otras actividades. El Ayuntamiento de Málaga no ha realizado ninguna modificación al respecto, con lo cual el problema de estos establecimientos sigue siendo en la actualidad un problema de difícil solución.

\section{El Plan Estratégico}

El Ayuntamiento de Málaga decidió promover en 1992 la realización del Plan Estratégico que se plasmó en una moción conjunta de todos los grupos políticos. A partir de esa decisión, el Alcalde-Presidente tomó la iniciativa de que fuese Málaga en su conjunto, a través de los agentes económicos y sociales, la protagonista del mismo. Posteriormente, en 1993 se constituye la Fundación «Centro de Investigaciones Estratégicas y de Desarrollo Social de Málaga» (CIEDES), que desde el momento de su constitución asume todo el proceso de planificación estratégica de Málaga.

El Plan Estratégico de Málaga fue impulsado por distintos tipos de agentes tanto públicos (gobierno regional, diputación y ayuntamiento) como privados (asociaciones de empresarios, cámara de comercio, consorcios, etc.) con el objetivo central de hacer de Málaga una ciudad metropolitana de alcance mediterráneo, metrópolis de alta calidad de vida y respeto medioambiental, capital económica y tecnológica de Andalucía, capital turística y de ocio europea (Fundación CIEDES, 1996).

El Plan Estratégico se estructura en cinco fases: 


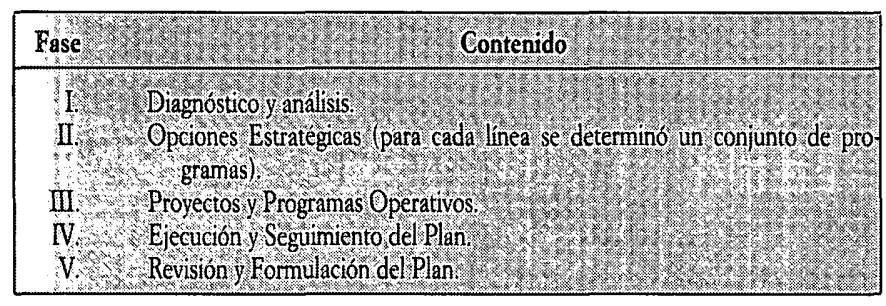

La Asociación Centro Histórico participó activamente en las fases previas, en las mesas de trabajo (mesas de turismo, ocio, comercio), para la elaboración del diagnóstico general y en la elaboración de las propuestas que integrarían las líneas estratégicas cuyo desarrollo se llevó a cabo mediante diversos programas. La labor más destacada se produjo en uno de los primeros veinte temas seleccionados por la Oficina de Coordinación del Plan Estratégico de Málaga. Concretamente en el dictamen sectorial de diagnosis de Málaga como centro comercial, en el que se cuestiona el liderazgo del comercio del centro histórico y su centralidad funcional desde el punto de vista no sólo comercial, sino de servicios, ocio y cultura. Al plantear el documento la «inexistencia de un centro urbano potente», proponiendo una doble polaridad fuera de éste. Por un lado, la consolidación de un comercio intraurbano en los alrededores de los grandes almacenes (aunque desde el rigor sólo se puede considerar gran almacén a uno de los formatos existentes en la zona, El Corte Inglés) y la creación ex novo de una polaridad comercial, casualmente coincidente con la zona de expansión urbana planificada de la ciudad en ese momento (eje frente litoral oeste).

La Asociación promueve un informe técnico a este dictamen previo en el que no sólo se demuestra la importancia de la ciudad de Málaga en el sector comercio, sino el papel predominante que ejerce, en el conjunto de ésta, el centro histórico, como polaridad central histórica en cuanto a una amplia oferta diversa, donde predomina el comercio complementado con hostelería, servicios profesionales, personales, ocio y cultura. El Plan Estratégico asume estas aportaciones de tal manera que, de negar la existencia de la centralidad ejercida por el comercio en el Núcleo Histórico, pasa a considerar que Málaga debe perseguir un modelo mediterráneo de su comercio en su área central. El modelo comercial para la ciudad pasa, por lo tanto, por la reformulación y potenciación del centro urbano comercial. Es necesario llegar a un amplio consenso para crear un espacio comercial central diferenciado en la ciudad: especializado y de calidad. El centro bistórico, incluido el Puerto, ba de cumplir este papel central (Fundación CIEDES, 1996). En la actualidad la Asociación Centro Histórico promueve, modera y coordina, junto con otras instituciones de la ciudad, el Foro Puerto Ciudad, con objeto de realizar el seguimiento a las actuaciones previstas en el Plan Especial del Puerto (en los muelles 1 y 2), dada la importancia que por la proximidad geográfica y las reper- cusiones que éstas tienen en la integración del puerto con la ciudad y más concretamente en la unión con el centro histórico.

\section{Iniciativa Comunitaria Urban}

El Ayuntamiento de Málaga emprendió en 1995 diversos programas cofinanciados con la Unión Europea estableciendo dos líneas de actuación; una de ellas consistió en la recuperación y revitalización del centro histórico.

\section{Los objetivos del Programa Urban consistían en:}

- Rehabilitación y revitalización del centro histórico. Constó de una serie de intervenciones físicas para la recuperación de espacios degradados y creación de espacios abiertos, ya que la reforma de las infraestructuras y de la edificación es un aspecto fundamental en la mejora de la calidad de vida de la zona, tanto para su población residente como para la que habitualmente acude por motivos comerciales y turísticos.

- Potenciar el desarrollo del tejido económico, incentivando a la iniciativa privada en la modernización de los medios productivos del pequeño empresariado ubicado en la zona.

- Asistencia social e inversión en equipamientos, en una zona con focos muy localizados de mendicidad, prostitución e inmigración.

Para la consecución de sus objetivos (rehabilitación física y medioambiental y la revitalización funcional, con el fomento de la actividad empresarial y especialmente la comercial para impulsar el desarrollo económico), la Iniciativa Urban se desarrolla en tres niveles: urbanístico, económico y social.

En el aspecto económico la Iniciativa Urban estableció dos líneas:

1. ${ }^{\mathrm{a}}$ Mejora de los medios productivos. Consistente en subvenciones a fondo perdido para la mejora externa de los establecimientos y la adquisición y renovación del mobiliario e instalaciones internas. El número de comercios subvencionados fue de 162 establecimientos.

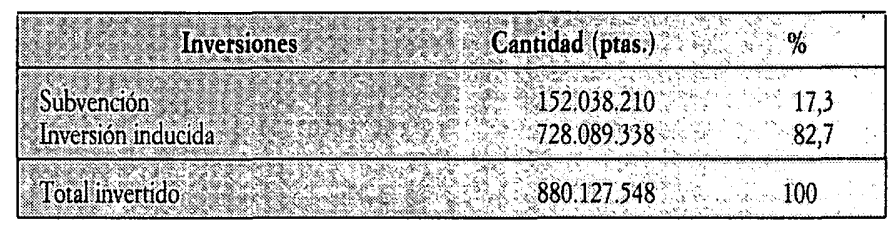

2. ${ }^{\text {a }}$ Promoción para el desarrollo. Se firmó un acuerdo entre PROMALAGA, S. A. (la entidad gestora de los fondos de la línea destinada al desarrollo económico) y la Asociación Centro Histórico, en la que ésta se comprometía a prestar servicios de asesoramiento a los comerciantes del centro histórico de Málaga en materia económica, fiscal, jurídica, laboral, tec- 
nológica y urbanística mediante los medios técnicos y humanos necesarios para ello, con carácter gratuito, y durante los ejercicios 1996 y 1997, e incentivar y promocionar el diseño y desarrollo de campañas de imagen, promoción y ventas, así como todas aquellas actuaciones a favor del centro histórico de la ciudad en este mismo período.

Aunque el acuerdo firmado finalizaba en el 1997, la Asociación continuó prestando servicios de asesoramiento a los comerciantes en materia de solicitud de subvenciones hasta que concluyó en 1999 la Iniciativa Comunitaria Urban; tanto en la línea referida como en la línea destinada a la rehabilitación de inmuebles que se gestionaba a través de la Oficina Municipal de Rehabilitación del Centro Histórico.

En la actualidad la relación Asociación-Ayuntamiento se puede definir como una colaboración abierta; así, de manera formal, se forma parte de:

- El Pleno de la Junta Municipal del Distrito Centro (y sus comisiones de trabajo).

- El Consejo Municipal de Medioambiente.

- La Junta Arbitral de Consumo.

De manera continuada, para resolución de problemas, de gestión y de planificación y cooperación se mantienen reuniones periódicas con las Concejalías de:

- Comercio, Industria y Empleo

- Cultura y Turismo

- Economía y Hacienda

- Urbanismo y Tráfico

- Medio Ambiente

- Servicios Operativos

- Seguridad.

\section{mancomunada del espacio}

3. Una vía hacia la gestión

El centro histórico debe gestionarse de manera unitaria, integrando en dicha gestión todas las variables que lo conforman (físicas, sociales, económicas y culturales) y a todos los agentes intervinientes. Nos referimos a una gestión en la que participen tanto la Administración Local como los agentes privados que operan en este espacio. La solución a los diversos y complejos problemas que presenta el centro histórico sólo se podrá solventar con una comprensión integral o globalizadora; por lo tanto, es imposible que fuera de la gestión unitaria pueda promoverse una revitalización real, estable y equilibrada. Como ejemplo de esta imposibilidad mostramos la historia de nuestra ciudad en los últimos veinticinco años: la coordinación y consenso entre Ayuntamiento y otras Administraciones, y agentes privados, en cuanto a estrategias, intervenciones y actuaciones, no ha mantenido una secuencia regular, provocando fracturas no sólo en el diálogo, sino en la efectividad de las actuaciones. La inexistencia de una entidad unitaria de gestión (Gerencia del Centro Urbano) con dotación presupuestaria para la aplicación de las actuaciones necesarias y una adecuada política de planificación y gestión, sin duda ha retardado el proceso de desarrollo y la efectividad en la gestión del centro.

Se necesita un gran consenso social, entre gobierno local y los agentes que operan en el centro (comerciantes y empresarios en general, a la vez que propietarios de inmuebles y residentes) en el que todas las partes implicadas estén dispuestas a apostar de manera decidida y conjunta por el centro histórico en beneficio de la ciudad y de sus ciudadanos.

El marco jurídico/legislativo español no contempla una figura específica que permita la participación en partenariado de lo público y lo privado en una gestión mancomunada del espacio. Por lo que se demanda una nueva fórmula jurídica que establezca el marco de coparticipación y cooperación para la gestión conjunta. Es necesario, por tanto, la creación de un modelo de gestión ad boc, que permita la participación de todos los agentes presentes en el centro con el propósito de hacer efectiva la puesta en valor y la revitalización integral del centro histórico de Málaga.

El órgano de gestión unitaria del centro histórico debe tener como objetivo principal la coordinación entre los agentes públicos y privados. La conjunción en las inversiones, en las líneas de actuación, en las políticas de planificación, en las acciones de promoción del centro, etc., son de vital importancia para conseguir un desarrollo integral, no obviando ninguno de los factores que configuran el centro, a la vez que se genera una fuerte sinergia que aisladamente no obtendría los mismos resultados. Por sí solos ni el Ayuntamiento ni la Asociación Centro Histórico podrán hacer frente a esta gestión, siendo necesaria una acción conjunta de inversiones, concentradas en un proyecto en el que exista implicación y fuerte compromiso tanto del gobierno local, y de otras Administraciones Públicas, como de los agentes privados.

En estos momentos el centro histórico de la ciudad de Málaga tiene la oportunidad de dar un paso adelante, ya que se mantienen conversaciones entre Ayuntamiento y Asociación Centro Histórico para la creación de un Consejo Municipal del Centro Histórico, que debería constituir el germen de la futura entidad: Gerencia del Centro Histórico.

La gestión unitaria del espacio debe fundamentarse en un proyecto sólido que marque unas directrices para la consecución 
de los objetivos perseguidos. La Asociación Centro Histórico, a tal fin, está desarrollando un Plan Director con las acciones a realizar para la revitalización del centro, para su incorporación al futuro Consejo Municipal del Centro.

El Plan se estructura de la siguiente manera:

—. Diagnóstico del centro histórico de Málaga.

- Análisis de la Demanda.

- Estudio de Imagen del centro histórico.

- Líneas de intervenciones y actuaciones.

El Plan Director de Revitalización Integral del centro histórico de Málaga tiene un período de desarrollo de cuatro años (2001-2004); como objetivo principal se propone la confluencia de las inversiones públicas y privadas que posibiliten la reactivación y promoción económica del Centro.

Las inversiones públicas deben dirigirse a:

- La mejora y mantenimiento del patrimonio inmobiliario (a través de líneas de rehabilitación, evitando en lo posible la renovación, ya que debemos conservar la identidad cultural que constituye el elemento singularizador de este espacio).

- Mejora del mobiliario urbano, aumentando el número y la calidad de los mismos, a la vez que una imagen homogénea del espacio público.

- Mejora de las infraestructuas. El grado de accesibilidad tanto de tráfico rodado como peatonal debe ser aumentado considerablemente. En la actualidad el Ayuntamiento está realizando un estudio para la peatonalización del Centro, proyecto que será consensuado, con la participación activa de la Asociación Centro Histórico como representante de la actividad económica que se desarrolla en la zona. Soterramiento del cableado exterior de los inmuebles. El cableado aparece de manera habitual en las fachadas de los inmuebles y cruzando las calles; esto provoca un elevado impacto visual que rompe con las normas de paisaje.

- Aumento de la dotación de las plazas de aparcamientos. Se están construyendo dos aparcamientos en el casco, insuficientes para acometer el proyecto de peatonalización que plantea el Ayuntamiento. Es necesario un sistema de aparcamientos periféricos al centro, conectado, por un lado, con las principales vías de tráfico rodado y, por otro, con las entradas peatonales del mismo. La carencia de plazas de aparcamiento y el posible desarrollo de un plan de peatonalización del Centro puede tener como consecuencia más directa la desertización del espacio, por el abandono de los consumidores y de los residentes; y más tarde, de la actividad económica (que en estos momentos representa el $14 \%$ del total de la ciudad).

- Aumento del equipamiento cultural de carácter público. En este período es fundamental la finalización de los proyectos en curso, como: el Museo Picasso, el museo de Bellas Artes y el Arqueológico, la Biblioteca Provincial y la definitiva aper- tura (tras las obras que se llevan acometiendo varios años) del conjunto-monumental Alcazaba-Teatro Romano.

Las inversiones privadas deben establecerse en un marco de:

- Compromiso de los agentes privados en la rehabilitación y conservación del patrimonio inmobiliario. Los propietarios de los inmuebles, como de los bajos comerciales, deben invertir en la mejora de éstos, con actuaciones que respeten las tipologías constructivas.

- Promoción del centro histórico como espacio unitario, caracterizado por ser un área de actividad económica densa (comercio, hostelería, servicios personales, profesionales, culturales). Realización de las actuaciones precisas para la promoción integral del espacio, basadas en las técnicas de city marketing.

- Nuevas implantaciones comerciales que cubran los huecos existentes en los nichos de mercado de la oferta sectorial que ofrece el centro. La consolidación de un mix comercial competitivo con respecto al resto de implantaciones comerciales de la ciudad.

- Renovación y modernización de las tipologías comerciales, de servicios, ocio, con el fin de aumentar el grado de atracción del conjunto de la actividad económica.

- Optimización de las localizacionés comerciales como consecución de una planificación comercial estratégica mediante la ordenación de los establecimientos en el espacio a través de técnicas fundamentadas en el geomarketing.

\section{Conclusiones finales}

La iniciativa en la revitalización del centro surge de los comerciantes y empresarios localizados en él. En el momento en el que la crisis que atraviesa este espacio llega a su nivel máximo y en el que el Ayuntamiento aún no ha planificado ninguna política de recuperación.

Habrá que esperar al PGOU de 1983 y al PEPRI para tener una normativa específica de planificación para la recuperación del centro; sin embargo, su falta de rigor en la aplicación propició que no pudiera cumplir con los objetivos comprometidos. Un factor demostrativo sería, como en la primera revisión del PEPRI, un gran número de los edificios protegidos sufren el siguiente proceso: bajan su nivel de protección o pierden la protección por el estado de ruina.

El nuevo PGOU (1997) no incorpora ningún cambio sustancial con respecto al anterior, en lo que respecta a las políticas de rehabilitación y comercio. 
No recoge una planificación comercial en la que:

- Se asocien las estrategias de modernización del comercio tradicional, al diseño de las políticas de renovación y rehabilitación del centro histórico.

- Se promuevan los desarrollos de uso-mixto y la salvaguarda de la dimensión residencial de los Centros, asegurando la satisfacción prioritaria de las necesidades de la población residente (Dirección General de Comercio Interior, Secretaría de Estado de Comercio, Turismo y de la Pequeña y Mediana Empresa, Ministerio de Economía y Hacienda, 1998).

La falta de resultados de los instrumentos de planificación expuestos, se palió en gran medida con una acertada actuación municipal mediante la aplicación de la Iniciativa Comunitaria Urban. La financiación de este programa fue de 2.322 millones de pesetas que generaron una inversión total de 5.172 millones. Una vez más se corrobora que una eficaz inversión pública estimula a la privada, logrando con ello una sinergia en la recuperación física y funcional del centro que de otro modo no se produciría.

A pesar de la importancia de las inversiones para la puesta en valor de los inmuebles y la recuperación de la actividad económica, no es válida por sí sola a largo plazo. Es necesario un proyecto común consensuado que incorpore los intereses y objetivos de todos los agentes y que permita una comprensión y gestión integral del espacio centro histórico.

En estos momentos el centro histórico de Málaga se encuentra en un proceso tanto de ajuste como de expectativa; la dualidad en la rehabilitación espacial se corrobora con áreas revitalizadas, frente a otras que están pendientes de las actuaciones que le permitan rehabilitar y recuperar su patrimonio edificatorio, funcional y simbólico.

" Asociación Centro Histórico de Málaga.

\section{Bibliografía}

Asociación Centro Histórico de Málaga (1996), Estatutos.

Asociación Gran Centro Comercial (1977), Estatutos

Ayuntamiento de Málaga (1983), Plan General de Ordenación Urbana.

Ayuntamiento de Málaga (1990), Plan Especial de Protección y Reforma Interior del Centro Histórico.

Ayuntamiento de Málaga (1995), Iniciativa Comunitaria Urban.

Ayuntamiento de Málaga (1997), Plan General de Ordenación Urbana.

Caballero Monros, E., y Álvarez de Toledo y Gross, R. (1972), «Plan General de Ordenación de Málaga», revista Ciudad y Territorio, núm. 2/72: 39-50.

Dirección General de Comercio Interior. Secretaría de Estado de Comercio, Turismo y PYME. Ministerio de Economía y Hacienda (1998), Comercio y Planeamiento Urbano, Madrid: Secretaría General Técnica, Centro de Publicaciones y Documentación del Ministerio de Economía y Hacienda.
Dirección General de Política Territorial y Urbanismo. Ministerio de Obras Públicas y Transportes (1992), Cascos Antiguos y Centros Históricos: problemas, políticas y dinámicas urbanas, Secretaría General Técnica.

Fundación CIEDES (1996), Plan Estratégico de Málaga, Málaga: Fundación CIEDES.

Instituto Municipal de la Vivienda (2000), Memoria de Gestión 95/99, Málaga: Instituto Municipal de la Vivienda.

Junta de Andalucía (1998), Plan Integral de Fomento del Comercio Interior de Andalucía. 1998-2001, Sevilla: Consejería de Trabajo e Industria. Junta de Andalucía.

Olano Gurriarán, C. (1972), «Estudio del desarrollo urbanístico de la ciudad de Málaga», revista Ciudad y Territorio, núm. 2/72: 25-37.

Plan Estratégico de Málaga (1993), Málaga como centro comercial. Documento: dictamen. Oficina de Coordinación.

Trortiño VinuesA, M. A. (1997), Centros Históricos: Planificación, revitalización, calidad ambiental y patrimonio. Curso de verano Universidad SEK, Segovia. 
